\title{
Genetic variations in circadian rhythm genes and susceptibility for myocardial infarction
}

\author{
Ivana Škrlec ${ }^{1,3}$ (D), Jakov Milic ${ }^{1}$, Marija Heffer ${ }^{1}$, Borut Peterlin ${ }^{2}$ and Jasenka Wagner ${ }^{1,3}$ \\ ${ }^{1}$ Department of Medical Biology and Genetics, Faculty of Medicine, J. J. Strossmayer University of Osijek, \\ Croatia \\ ${ }^{2}$ Clinical Institute of Medical Genetics, University Medical Center Ljubljana, Slovenia. \\ ${ }^{3}$ Faculty of Dental Medicine and Health, J. J. Strossmayer University of Osijek, Croatia.
}

\begin{abstract}
Disruption of endogenous circadian rhythms has been shown to increase the risk of developing myocardial infarction (MI), suggesting that circadian genes might play a role in determining disease susceptibility. We conducted a case-control study on 200 patients hospitalized due to $\mathrm{Ml}$ and 200 healthy controls, investigating the association between $\mathrm{Ml}$ and single nucleotide polymorphisms (SNPs) in four circadian genes (ARNTL, CLOCK, CRY2, and PER2). The variants of all four genes were chosen based on their previously reported association with cardiovascular risk factors, which have a major influence on the occurrence of myocardial infarction. Statistically significant differences, assessed through Chi-square analysis, were found in genotype distribution between cases and controls of the PER2 gene rs35333999 ( $p=0.024)$ and the $C R Y 2$ gene rs2292912 ( $p=0.028)$; the corresponding unadjusted odds ratios, also significant, were respectively $\mathrm{OR}=0.49(95 \% \mathrm{Cl} 0.26-0.91)$ and $\mathrm{OR}=0.32(95 \% \mathrm{Cl} 0.11-0.89)$. Our data suggest that genetic variability in the $C R Y 2$ and $P E R 2$ genes might be associated with myocardial infarction.
\end{abstract}

Keywords: cardiovascular diseases, circadian rhythm, myocardial infarction, polymorphisms.

Received: May 23, 2017; Accepted: October 22, 2017.

Cardiovascular diseases (CVD) are the world's leading cause of death (WHO, 2015), and myocardial infarction (MI) is the third leading cause of mortality in Croatia (Hrabak Zerjavic et al., 2010). In the last few years, genome-wide association studies (GWAS) have identified many genetic variants that contribute to a higher risk of MI (Erdmann et al., 2010). Despite numerous studies conducted on MI, its etiology is still largely unknown.

Human physiological activities and diseases are under the control of circadian rhythm. Several physiological factors can cause MI, and several of these factors are known to oscillate with circadian rhythm (Kanth et al., 2013). Some of those are blood pressure (Woon et al., 2007; Englund et al., 2009; Dashti et al., 2014), glucose homeostasis (Dashti et al., 2014; Lipkova et al., 2014), vascular endothelial function, myocardial contractile function and metabolism (Ebisawa et al., 2001; Martino and Sole, 2009; Bonney et al., 2013a,b).

Epidemiological studies found daylight to be the leading regulator of the human circadian rhythm, and sunlight cycles are crucial for keeping a healthy cardiovascular

Send correspondence to Ivana Škrlec. Department of Medical Biology and Genetics, Faculty of Medicine, Josipa Huttlera 4, 31000 Osijek, Croatia. E-mail: iskrlec@mefos.hr. system (Bonney et al., 2013a,b). In humans, relevant relationships exist between circadian clocks and the metabolic syndrome (Englund et al., 2009).

There is increasing evidence that circadian rhythms have an important role in preserving homeostasis and appropriate body function including cardiac metabolism (Woon et al., 2007; Englund et al., 2009; Bonney et al., 2013a,b; Corella et al., 2016). In the mutant mouse models is emphasized that mutations in the PER2 gene were associated with protection from myocardial ischemia (Bonney et al., 2013a,b).

Circadian clock network consists of molecular components where ARNTL, CLOCK, CRY2 and PER2 genes represent the central node in the network (Corella et al., 2016). Those core clock genes establish the internal clock and constitute negative and positive transcriptional and translational feedback loops. Heterodimers of the ARNTL/CLOCK proteins initiate the transcription of the $C R Y 2, P E R 2$, and other clock-related genes. Heterodimers of the CRY2/PER2 proteins assemble the negative feedback loop and inhibit the transcriptional activity of the ARNTL and CLOCK genes (Takeda and Maemura, 2010, 2016).

The aim of this study was to explore a possibility of association of the genetic variability of the ARNTL, $C L O C K, C R Y 2$ and PER2 genes with myocardial infarction 
in humans. We implemented a case-control study on a population of patients with myocardial infarction in comparison with a control population. The study was conducted from August 2012 to December 2013. Patients with myocardial infarction were hospitalized at the Clinical Department of Cardiovascular Diseases and Intensive Care at the University Hospital Osijek, Croatia.

Myocardial infarction was defined as the presence of at least two of the following: typical increase of biochemical marker of myocardial necrosis - cardiac troponin $\mathrm{T}$ (above the $99^{\text {th }}$ percentile), ischemic chest pain symptoms lasting more than 30 minutes, and electrocardiography changes (ECG) indicative of ischemia (ST-segment elevation or depression) (Thygesen et al., 2012). Thirty-eight patients were excluded from this study because they did not meet the criteria as mentioned above or they had a percutaneous coronary intervention or coronary artery bypass grafting. Fifty-three patients refused to participate in the study, and nine patients drop out of the study.

The control group consisted of 200 healthy sex- and age-matched participants, whose medical documentation did not show any history of cardiovascular diseases. Their primary care physician chose them in an ambulatory. We excluded any patient's relatives from the control group because of complex heritability of cardiovascular risk factors showed in monozygotic twins (Elder et al., 2009).

Systematic information on the medical history was collected from all participants. The questionnaire included questions about age, history of smoking, hypertension, dyslipidemia, respiratory diseases, diabetes mellitus, kidney and liver diseases. All given information was checked in patient's medical record.

This study was approved by the Ethics Committee of the Faculty of Medicine, the Josip Juraj Strossmayer University of Osijek (No. 2158-61-07-12-21) and by the Ethics Committee of the University Hospital Osijek (No. 251:3160-3/2012). The study was conducted according to the Declaration of Helsinki and its amendments. Written informed consent was obtained from all participants in the study.

In this study, genetic variants were genotyped in four key circadian rhythm regulating genes, ARNTL, CLOCK, $C R Y 2$, and PER2. Ten SNPs previously associated with cardiovascular risk factors were investigated. Six single nucleotide polymorphisms (SNPs) were chosen from ARNTL and CLOCK genes. Of these, three SNPs, rs3789327, rs4757144, and rs12363415 in the ARNTL gene, and three SNPs, rs11932595, rs6811520, and rs13124436 were selected in the CLOCK gene. Two SNPs, rs2292912 and rs10838524 in the CRY2 gene, and two SNPs, rs35333999, and rs934945 were selected in the PER2 gene.

Genomic DNA was extracted from the peripheral blood lymphocyte using standard procedures (QIAamp DNA Blood Mini Kit, Qiagen, Hilden, Germany). Genotyping was carried out by real-time PCR method performed on 7500 Real-Time PCR System (Applied Biosystems,
Foster City, CA, USA) using TaqMan SNP genotyping assays. The PCR reaction mix of $6.25 \mu \mathrm{L}$ final volume consisted of $6 \mathrm{ng}$ of genomic DNA, $3.13 \mu \mathrm{L}$ of TaqMan Universal PCR Master Mix 2X, $0.15 \mu \mathrm{L}$ Assay Mix 40X, and $2.17 \mu \mathrm{L} \mathrm{ddH_{2 }}$ O. The protocol for PCR amplification was: initial denaturation step at $95^{\circ} \mathrm{C}$ for $10 \mathrm{~min}$, then 40 cycles of denaturation at $92{ }^{\circ} \mathrm{C}$ for $15 \mathrm{~s}$, followed by $60{ }^{\circ} \mathrm{C}$ for 1 min, and a final extension at $60{ }^{\circ} \mathrm{C}$ for $1 \mathrm{~min}$. The allelic discrimination analysis was performed using SDS 7500 Software Version 2.3 (Applied Biosystems, Foster City, CA, USA).

Chi-square tests $\left(\chi^{2}\right)$ on contingency tables were used to compare allelic and genotype frequencies in controls and cases. To further assess the presence of associations, we calculated, for the indicated genetic risk factors, the odds ratios (OR) and their respective $95 \%$ confidence intervals (CI). Analyses were performed using SHEsis web tool (Shi and $\mathrm{He}, 2005$; Li et al., 2009). An additional level of genotyping quality control was performed using Chi-Square goodness-of-fit test, by comparing our genotype distribution with those predicted by Hardy-Weinberg equilibrium. Associations were considered significant when they reached the $p$-value of equal to or less than 0.05 . Appropriate corrections of significance values were also applied using the Benjamini-Hochberg correction method (false-discovery rate - FDR values) because of multiple SNPs were investigated. The $q$ values of less than 0.05 were considered to be significant. As the participants of the study were not related, haplotypes and the pairwise linkage disequilibrium (LD) were estimated using SNPStats web tool (Solé et al., 2006).

The prevalence of cardiovascular risk factors among all participants included in the study sample is summarized in Table 1 . The mean age of the study population was $64 \pm$

Table 1 - Prevalence of cardiovascular risk factors among all participants included in the study by groups.

\begin{tabular}{lccc}
\hline Variables & $\begin{array}{c}\text { Patients } \\
(\mathrm{n}=200)\end{array}$ & $\begin{array}{c}\text { Controls } \\
(\mathrm{n}=200)\end{array}$ & $p$-value \\
\hline Age year mean (SD) & $66 \pm 12$ & $62 \pm 13$ & 0.086 \\
Gender: males & $114(57 \%)$ & $104(52 \%)$ & 0.317 \\
Smoking & & & \\
Non-smokers & $99(49.5 \%)$ & $151(75.5 \%)$ & $<0.001$ \\
Smokers & $41(20.5 \%)$ & $39(19.5 \%)$ & \\
Former smokers & $60(30 \%)$ & $10(5 \%)$ & \\
Hypertension & $107(53.5 \%)$ & $59(29.5 \%)$ & $<0.001$ \\
Dyslipidemia & $26(13 \%)$ & $23(11.5 \%)$ & 0.648 \\
Respiratory disease & $2(1.8 \%)$ & $8(4 \%)$ & 0.055 \\
Diabetes mellitus 2 & $44(22 \%)$ & 0 & - \\
Kidney diseases & $15(7.5 \%)$ & $12(6 \%)$ & 0.550 \\
Liver disease & $10(5 \%)$ & $9(4.5 \%)$ & 0.814 \\
\hline
\end{tabular}

Numerical variables are presented as mean (SD), while categorical variables as number (percentage). 
13 years, and $54.5 \%$ were males. Genotype frequencies of investigated polymorphisms were predicted by the HardyWeinberg equilibrium in the study and the control group ( $p$ $>0.05$ ), except for rs6811520, which was excluded from further analyses. Minor allele frequencies of the almost all investigated SNPs are consistent with a reference population of HapMap phase 3, CEU; the exception was rs35333999 in the PER2 gene and rs6811520 in the
CLOCK gene (Table 2). Genotype and allelic distribution of the ARNTL, CLOCK, CRY2 and PER2 polymorphisms of the $200 \mathrm{MI}$ patients and 200 healthy controls are shown in Table 2.

We did not find any significant associations between rs3789327, rs4757144, and rs12363415 in the ARNTL gene and MI, and there was no significant difference comparing the frequencies of four the most frequent haplotypes for the

Table 2 - Allele and genotype distribution and frequencies of the ARNTL, CLOCK, CRY2 and PER2 polymorphisms.

\begin{tabular}{|c|c|c|c|c|c|c|c|c|c|c|c|}
\hline \multirow[t]{2}{*}{ Gene } & \multirow[t]{2}{*}{ SNP } & \multirow{2}{*}{$\begin{array}{c}\text { Minor } \\
\text { allele }\end{array}$} & \multirow{2}{*}{$\begin{array}{c}\text { MAF* } \\
\text { patients }\end{array}$} & \multirow{2}{*}{$\begin{array}{l}\text { MAF* } \\
\text { controls }\end{array}$} & \multirow[t]{2}{*}{$p$-value } & \multirow[t]{2}{*}{ Genotype } & \multicolumn{5}{|c|}{ Genotype frequency (\%) } \\
\hline & & & & & & & Patients with MI & Controls & $p$-value & $\mathrm{X}^{2}$ & q value \\
\hline \multirow[t]{9}{*}{ ARNTL1 } & rs3789327 & $\mathrm{C}$ & 0.42 & 0.44 & 0.475 & $\mathrm{CC}$ & 33.5 & 34.0 & 0.301 & 2.34 & 0.443 \\
\hline & & & & & & $\mathrm{CT}$ & 50.0 & 44.0 & & & \\
\hline & & & & & & $\mathrm{TT}$ & 16.5 & 22.0 & & & \\
\hline & rs4757144 & A & 0.62 & 0.59 & 0.385 & AA & 39.5 & 36.0 & 0.694 & 0.73 & 0.867 \\
\hline & & & & & & $\mathrm{AG}$ & 45.5 & 46.5 & & & \\
\hline & & & & & & GG & 15.0 & 17.5 & & & \\
\hline & rs1236341 & G & 0.15 & 0.17 & 0.501 & AA & 71.0 & 71.0 & 0.120 & 4.24 & 0.300 \\
\hline & & & & & & $\mathrm{AG}$ & 27.5 & 24.0 & & & \\
\hline & & & & & & GG & 1.5 & 5.0 & & & \\
\hline \multirow[t]{9}{*}{ CLOCK } & $\begin{array}{c}\text { rs1193259 } \\
5\end{array}$ & G & 0.39 & 0.39 & 0.942 & AA & 36.5 & 35.0 & 0.878 & 0.26 & 0.878 \\
\hline & & & & & & AG & 49.5 & 52.0 & & & \\
\hline & & & & & & GG & 14.0 & 13.0 & & & \\
\hline & rs6811520 & $\mathrm{T}$ & 0.39 & 0.49 & 0.004 & $\mathrm{CC}$ & 37.5 & 31.0 & 0.005 & 10.55 & 0.050 \\
\hline & & & & & & $\mathrm{CT}$ & 47.0 & 40.0 & & & \\
\hline & & & & & & $\mathrm{TT}$ & 15.5 & 29.0 & & & \\
\hline & $\begin{array}{c}\text { rs } 1312443 \\
6\end{array}$ & A & 0.33 & 0.28 & 0.143 & AA & 11.0 & 7.0 & 0.294 & 2.45 & 0.443 \\
\hline & & & & & & $\mathrm{AG}$ & 43.0 & 41.5 & & & \\
\hline & & & & & & GG & 46.0 & 51.5 & & & \\
\hline \multirow[t]{6}{*}{$C R Y 2$} & rs2292912 & G & 0.20 & 0.26 & 0.054 & $\mathrm{CC}$ & 62.0 & 55.5 & 0.056 & 5.78 & 0.197 \\
\hline & & & & & & $\mathrm{CG}$ & 35.5 & 37.0 & & & \\
\hline & & & & & & GG & 2.5 & 7.5 & & & \\
\hline & $\begin{array}{c}\mathrm{rs} 1083852 \\
4\end{array}$ & A & 0.45 & 0.49 & 0.230 & AA & 19.0 & 26.3 & 0.212 & 3.11 & 0.424 \\
\hline & & & & & & $\mathrm{AG}$ & 52.5 & 46.5 & & & \\
\hline & & & & & & GG & 28.5 & 27.2 & & & \\
\hline \multirow[t]{6}{*}{ PER2 } & $\begin{array}{c}\text { rs } 3533399 \\
9\end{array}$ & $\mathrm{~T}$ & 0.05 & 0.09 & 0.032 & $\mathrm{CC}$ & 91.5 & 84.0 & 0.059 & 5.64 & 0.197 \\
\hline & & & & & & $\mathrm{CT}$ & 7.5 & 15.0 & & & \\
\hline & & & & & & $\mathrm{TT}$ & 1.0 & 1.0 & & & \\
\hline & rs934945 & $\mathrm{T}$ & 0.17 & 0.19 & 0.644 & $\mathrm{CC}$ & 69.0 & 67.5 & 0.864 & 0.29 & 0.878 \\
\hline & & & & & & $\mathrm{CT}$ & 27.5 & 28.0 & & & \\
\hline & & & & & & TT & 3.5 & 4.5 & & & \\
\hline
\end{tabular}

*MAF - minor allele frequency

Pearson Chi-square test

CLOCK SNP rs6811520 showed a departure from the Hardy-Weinberg equilibrium and was excluded $p$-values shown in the table are corrected for the multiple comparisons. 
three analyzed SNPs in the ARNTL gene in the patients and control groups.

The SNPs in the CLOCK gene, rs11932595, and rs13124436 did not show significant association of genotype or allelic distribution between the patients and control groups. Accordingly, we did not find any significant difference when comparing the frequencies of four most frequent haplotypes for the two analyzed SNPs in the CLOCK gene in the study and control groups.

No significant associations were found between the rs2292912 and rs10838524 SNPs of the CRY2 gene and MI. Under the recessive genotype model ( $\mathrm{GG}$ versus $\mathrm{CC}+\mathrm{CG}$ ), OR of 0.32 was estimated for the $C R Y 2$ gene polymorphism rs2292912 $(p=0.028$, OR $=0.32$ with $95 \%$ CI $0.11-0.89)$ (Table 3). We did not find any significant difference when comparing the frequencies of the three most frequent haplotypes for the two analyzed SNPs in the CRY2 gene in the patients and control groups.

A statistically significant difference was seen in the allelic distribution of rs35333999 $(p=0.033)$ in the PER2 gene. However, we did not find any significant association between the rs 934945 polymorphism of the PER 2 gene and MI. Under the dominant genotype model (TT $+\mathrm{CT}$ versus $\mathrm{CC}$ ), an OR of 0.49 was estimated for the PER2 gene polymorphism rs35333999 $(p=0.024, \mathrm{OR}=0.49$ with $95 \% \mathrm{CI}$ 0.26-0.91) (Table 3).

We analyzed the completed haplotypes in the four investigated genes. Table 4 shows the frequencies of predicted haplotypes in the patients and the control group. A statistically significant difference in haplotype distributions was confirmed at the PER2 gene locus when comparing the frequency of haplotype TC $(p=0.033)$ between participants with MI and control group.

Linkage disequilibrium calculated for the $C L O C K$ gene SNPs (rs11932595 and rs13124436) were $\mathrm{D}^{\prime}=0.06$, $\mathrm{r}^{2}=0.001$. SNPs in the $C R Y 2$ gene were in $\mathrm{LD}\left(\mathrm{D}^{\prime}=0.97\right.$, $\mathrm{r}^{2}=0.31$ ). There was no LD between SNPs in the ARNTL gene, LD between rs4757144 and rs12363415 was $D^{\prime}=0.15, r^{2}=0.001$, between $r s 3789327$ and $r s 4757144$ was $D^{\prime}=0.10, r^{2}=0.01$, and between rs 3789327 and $\mathrm{rs} 12363415$ was $\mathrm{D}^{\prime}=0.61, \mathrm{r}^{2}=0.09$. LD for SNPs in the PER2 gene (rs35333999 and rs934945) was $\mathrm{D}^{\prime}=0.001, \mathrm{r}^{2}=0.01$.

In this case-control study we found an association between MI and gene variants of the CRY2 and PER2 gene in a sample of 400 participants. The circadian clock is a 24-hour internal system that allows an organism to maintain environmental changes and acclimate to them. Therefore, circadian rhythms handle a broad diversity of physiological and metabolic functions, and any interruption of these rhythms may influence on human health.

Two feedback loops, ARNTL/CLOCK and CRY/PER control expression of downstream transcription factors which regulate downstream target genes involved in different biochemical pathways, such as metabolism of glucose and lipids, synthesis of cholesterol, and others (Staels, 2006). A small number of studies have considered the role of the circadian rhythm in MI. One suggested that gene expression of the cardiomyocyte circadian clock influences myocardial contractile function, metabolism and gene expression (Bray et al., 2008). Another showed that in the cardiomyocyte-specific circadian clock mutant mice, the clock is a direct regulator of triglyceride metabolism in the heart (Tsai et al., 2010), while deletion of ARNTL in mice adipocyte resuled in obesity (Paschos et al., 2012).

PER2 is involved in the regulation of fatty acid metabolism with increased oxygen consumption (Grimaldi et al., 2010). Lipolysis was markedly attenuate in circadian clock mutant mice hearts, and there is a potential explanation for accelerated metabolic pathologies, such as atherosclerosis which might lead to MI in patients (Tsai et al., 2010). PER2 knock-out mice had larger infarct sizes, and the cardiac PER2 have an important role in fatty acid me-

Table 3 - Genotype models of the ARNTL, CLOCK, CRY2 and PER2 polymorphisms.

\begin{tabular}{|c|c|c|c|c|c|c|c|c|c|}
\hline \multicolumn{4}{|c|}{ Dominant model } & \multicolumn{3}{|c|}{ Recessive model } & \multicolumn{3}{|c|}{ odominant model } \\
\hline ARNTL1 & $p$ & OR & $95 \% \mathrm{CI}$ & $p$ & OR & $95 \% \mathrm{CI}$ & $p$ & OR & $95 \% \mathrm{CI}$ \\
\hline rs3789327 & 0.916 & 0.98 & $0.65-1.48$ & 0.163 & 0.70 & $0.42-1.16$ & 0.229 & 0.79 & $0.53-1.17$ \\
\hline rs4757144 & 0.498 & 0.83 & $0.49-1.42$ & 0.470 & 1.16 & $0.77-1.74$ & 0.841 & 1.04 & $0.7-1.54$ \\
\hline rs12363415 & 0.780 & 1.07 & $0.69-1.66$ & 0.040 & 3.53 & $0.95-13.14$ & 0.423 & 0.83 & $0.53-1.31$ \\
\hline \multicolumn{10}{|l|}{ CLOCK } \\
\hline rs11932595 & 0.770 & 1.09 & $0.61-1.95$ & 0.754 & 1.07 & $0.71-1.61$ & 0.617 & 1.10 & $0.75-1.64$ \\
\hline rs13124436 & 0.271 & 0.80 & $0.54-1.19$ & 0.162 & 1.63 & $0.81-3.38$ & 0.761 & 0.94 & $0.63-1.40$ \\
\hline \multicolumn{10}{|l|}{$C R Y 2$} \\
\hline rs2292912 & 0.187 & 0.76 & $0.51-1.14$ & 0.028 & 0.32 & $0.11-0.89$ & 0.051 & 0.35 & $0.12-1.01$ \\
\hline rs 10838524 & 0.785 & 0.94 & $0.61-1.46$ & 0.084 & 0.66 & $0.41-1.06$ & 0.082 & 0.64 & $0.39-1.06$ \\
\hline \multicolumn{10}{|l|}{ PER2 } \\
\hline rs35333999 & 0.024 & 0.49 & $0.26-0.91$ & 1 & 1 & $0.14-7.17$ & 0.509 & 0.50 & $0.06-3.91$ \\
\hline rs934945 & 0.747 & 0.93 & $0.61-1.42$ & 0.611 & 0.77 & $0.28-2.11$ & 0.665 & 0.79 & $0.28-2.27$ \\
\hline
\end{tabular}

$p$-values shown in the table are corrected for the multiple comparisons. 
Table 4 - Frequencies and distribution of probable haplotypes in the patients and the control groups.

\begin{tabular}{|c|c|c|c|c|c|c|}
\hline Gene & rs3789327 & rs4757144 & rs12363415 & Frequency patients & Frequency controls & $p$-value \\
\hline$A R N T L$ & $\mathrm{~T}$ & G & A & 0.16 & 0.19 & 0.562 \\
\hline$A R N T L$ & $\mathrm{C}$ & A & A & 0.16 & 0.18 & 0.604 \\
\hline$A R N T L$ & $\mathrm{C}$ & G & A & 0.13 & 0.13 & 0.627 \\
\hline ARNTL & $\mathrm{T}$ & $\mathrm{A}$ & A & 0.39 & 0.35 & 0.073 \\
\hline CLOCK & rs11932595 & rs13124436 & & & & \\
\hline CLOCK & A & G & & 0.36 & 0.39 & 0.381 \\
\hline CLOCK & G & G & & 0.32 & 0.33 & 0.820 \\
\hline CLOCK & A & A & & 0.25 & 0.21 & 0.276 \\
\hline CLOCK & G & $\mathrm{A}$ & & 0.07 & 0.06 & 0.776 \\
\hline CRY2 & rs2292912 & rs10838524 & & & & \\
\hline$C R Y 2$ & $\mathrm{C}$ & A & & 0.25 & 0.24 & 0.616 \\
\hline$C R Y 2$ & $\mathrm{C}$ & G & & 0.54 & 0.50 & 0.232 \\
\hline CRY2 & $\mathrm{G}$ & $\mathrm{A}$ & & 0.19 & 0.26 & 0.052 \\
\hline PER2 & rs35333999 & rs934945 & & & & \\
\hline PER2 & $\mathrm{C}$ & $\mathrm{C}$ & & 0.78 & 0.73 & 0.101 \\
\hline PER2 & $\mathrm{C}$ & $\mathrm{T}$ & & 0.17 & 0.19 & 0.646 \\
\hline PER2 & $\mathrm{T}$ & $\mathrm{C}$ & & 0.05 & 0.09 & 0.033 \\
\hline
\end{tabular}

tabolism and inflammation during myocardial ischemia and reperfusion (Bonney et al., 2013b).

Depletion of glycogen stores leads to increased infarct sizes in PER2 mutated mice because of reduced glycolysis during myocardial ischemia (Eckle et al., 2012). It has been shown that the protein PER2 has a cardioprotective role during myocardial ischemia in mice (Bonney et al., 2013a), and mutation of the PER2 gene is associated with a shorter circadian period during constant darkness (Vukolic et al., 2010). The study of Suarez-Barrientos et al. (2011) found that infarct size was larger in the early morning, what is similar to the findings that light-dependent stabilization of PER2 had cardioprotection role in ischemia (Eckle et al., 2012).

Genetic variations in the PER2 gene are associated with abdominal obesity (Garaulet et al., 2010) and metabolic syndrome (Garcia-Rios et al., 2012) due to its part in the lipid metabolism. PER2 activation during ischemia regulates fatty acid beta-oxidation during ischemia and inflammation during reperfusion by increasing inflammatory cytokines, metabolism and inflammation are connected, and inflammation can be a consequence of pathologic metabolism (Bonney et al., 2013b). Thereby, patients who have metabolic syndrome and higher inflammatory markers are at greater risk to develop CVD (Haffner, 2006). Although the genetic variation rs35333999 in the PER2 gene and rs2292912 in the CRY2 gene were associated with MI in this study, they are not precise because of the broad $95 \%$ CI values.

Disruption of the circadian clock has been implicated in the pathogenesis of cardiovascular disease, for which hypertension is a major factor (Kovanen et al., 2015). Aortic endothelial dysfunction with decreased production of nitric oxide was found in the mice with the mutated PER2 gene, as well as, decreased vasodilatory prostaglandins and elevated the release of cyclooxygenase-1-derived vasoconstrictors (Scott, 2015). In endothelial hemostatic function CLOCK, thrombomodulin, and plasminogen activator inhibitor-1 are involved. A circadian clock controls those genes in endothelial cells (Scott, 2015), and disruption of those genes might lead to atherosclerosis and MI. Some genetic variants of the CLOCK gene are related to obesity (Bandín et al., 2013; Garcia-Rios et al., 2012), metabolic syndrome, and CVD (Garcia-Rios et al., 2012).

The links from genetic variants to physiologic functions are most likely less than predicted, a study identified increased weight and obesity and features of metabolic syndrome as characteristics of CLOCK-deficient mice (Turek et al., 2005). Studies on CLOCK mutant mouse indicate an important role of myocardial CLOCK gene in energy metabolism, myocardial contractility, and in the diurnal heart rate control (Scott, 2015). In response to a high-fat diet, mutations in BMAL1 and CLOCK genes adjust circadian variation in glucose and triglycerides levels and affect the progress of insulin resistance (Scott, 2015).

Circadian rhythm has a significant role in regulating glucose metabolism, and cryptochromes are critical components of the circadian system in regulating glucose homeostasis (Kelly et al., 2012; Lipkova et al., 2014), dysregulation of which can lead to diabetes mellitus type 2 . Genetic variations of the BMAL1 gene, the mouse analog of the human $A R N T L$ gene, are associated with diabetes mellitus type 2 and hypertension, providing evidence for the role of $A R N T L$ variants in the pathology of the metabolic syndrome in human (Woon et al., 2007). 
Human studies have identified genetic variants and expression patterns of circadian clock genes, such as ARNTL, CLOCK, CRY2, NPAS2 or PER2, that are associated with metabolic syndrome, hypertension or diabetes mellitus type 2 (Ohkura et al., 2006; Scott, 2015). Circadian clock genes play a major role in hemostatic balance by regulating the fibrinolytic systems, and CLOCK and CRY genes are directly involved in this activity (Ohkura et al., 2006), and therefore increase the risk for CVD. A role of the circadian rhythm in cardiovascular function is firmly supported in all those studies, but our study found the connection of myocardial infarction and some of the circadian rhythm genes SNPs.

Although some of the obtained results are significant, they are hardly suitable for diagnosis and prognosis purposes. A limitation of our study is its sample size. The sample size was relatively small and could yield false positive results. Furthermore, the high ORs and broad $95 \%$ CIs, as well as the low frequency of some genotypes does not allow adjusting for clinical and demographic confounders (i.e., multiple regression analysis), and low frequency of some genotypes may have resulted in insufficient statistical power to detect a positive association. For participants in control groups, there is a risk of developing some of the CVD.

In conclusion, we provide data indicating that genetic variability in the $C R Y 2$ and $P E R 2$ genes may be associated with MI. This suggests a role for the circadian rhythm in the development of myocardial infarction, but genetic variations in ARNTL and CLOCK genes are not directly associated with MI. Further verification and mechanistic analysis of the circadian system in MI are possible.

\section{Acknowledgments}

This work was supported by the Josip Juraj Strossmayer University of Osijek, Croatia - UNIOS project 'Variation in circadian rhythm genes in patients with myocardial infarction' under grant number IZIP-2014-150.

\section{References}

Bandín C, Martinez-Nicolas A, Ordovás JM, Ros Lucas JA, Castell P, Silvente T, Madrid JA and Garaulet M (2013) Differences in circadian rhythmicity in CLOCK $3111 \mathrm{~T} / \mathrm{C}$ genetic variants in moderate obese women as assessed by thermometry, actimetry and body position. Int $\mathrm{J}$ Obes 37:1044-50.

Bonney S, Hughes K, Harter, PN, Mittelbronn M, Walker L and Eckle T (2013a) Cardiac period 2 in myocardial ischemia: Clinical implications of a light dependent protein. Int $\mathrm{J}$ Biochem Cell Biol 45:667-71.

Bonney S, Kominsky D, Brodsky K, Eltzschig H, Walker L and Eckle T (2013b) Cardiac Per2 functions as novel link between fatty acid metabolism and myocardial inflammation during ischemia and reperfusion injury of the heart. PloS One 8:e71493.
Bray MS, Shaw CA, Moore MWS, Garcia RAP, Zanquetta MM, Durgan DJ, Jeong WJ, Tsai JY, Bugger H, Zhang D, et al. (2008) Disruption of the circadian clock within the cardiomyocyte influences myocardial contractile function, metabolism, and gene expression. Am J Physiol Heart Circ Physiol 294:H1036-H1047.

Corella D, Asensio EM, Coltell O, Sorlí JV, Estruch R, MartínezGonzález MÁ, Salas-Salvado J, Castaner O, Aros F, Laperta $\mathrm{J}$, et al. (2016) CLOCK gene variation is associated with incidence of type- 2 diabetes and cardiovascular diseases in type-2 diabetic subjects: dietary modulation in the PREDIMED randomized trial. Cardiovasc Diabetol 15:4.

Dashti HS, Smith CE, Lee YC, Parnell LD, Lai CQ, Arnett DK, Ordovas JM and Garaulet M (2014) CRY1 circadian gene variant interacts with carbohydrate intake for insulin resistance in two independent populations: Mediterranean and North American. Chronobiol Int 31:660-7.

Ebisawa T, Uchiyama M, Kajimura N, Mishima K, Kamei Y, Katoh M, Watanabe T, Sekimoto M, Shibui K, Kim K, et al. (2001) Association of structural polymorphisms in the human period3 gene with delayed sleep phase syndrome. EMBO Rep 2:342-6.

Eckle T, Hartmann K, Bonney S, Reithel S, Mittelbronn M, Walker LA, Lowes BD, Han J, Borchers CH, Buttrick PM, et al. (2012) Adora2b-elicited Per2 stabilization promotes a HIF-dependent metabolic switch crucial for myocardial adaptation to ischemia. Nat Med 18:774-82.

Elder SJ, Lichtenstein AH, Pittas AG, Roberts SB, Fuss PJ, Greenberg AS, McCrory MA, Bouchard TJ Jr, Saltzman E and Neale MC (2009) Genetic and environmental influences on factors associated with cardiovascular disease and the metabolic syndrome. J Lipid Res 50:1917-1926.

Englund A, Kovanen L, Saarikoski ST, Haukka J, Reunanen A, Aromaa A, Lonngvist J and Partonen T (2009) NPAS2 and PER2 are linked to risk factors of the metabolic syndrome. J Circadian Rhythms 7:5.

Erdmann J, Linsel-Nitschke P and Schunkert H (2010) Genetic causes of myocardial infarction: new insights from genome-wide association studies. Dtsch Ärztebl Int 107:694-9.

Garaulet M, Corbalán-Tutau MD, Madrid JA, Baraza JC, Parnell LD, Lee YC and Ordovas JM (2010) PERIOD2 variants are associated with abdominal obesity, psycho-behavioral factors, and attrition in the dietary treatment of obesity. J Am Diet Assoc 110:917-21.

Garcia-Rios A, Perez-Martinez P, Delgado-Lista J, Phillips CM, Gjelstad IMF, Wright JW, Karlstrom B, Kiec-Wilk B, van Hess AM, Helal O, et al. (2012) A Period 2 genetic variant interacts with plasma SFA to modify plasma lipid concentrations in adults with metabolic syndrome. J Nutr 142:1213-8.

Grimaldi B, Bellet MM, Katada S, Astarita G, Hirayama J, Amin RH, Granneman JG, Piomelli D, Leff T and Sassone-Corsi P. (2010) PER2 controls lipid metabolism by direct regulation of PPAR $\gamma$. Cell Metab 12:509-520.

Haffner SM. (2006) The metabolic syndrome: Inflammation, diabetes mellitus, and cardiovascular disease. Am J Cardiol 97:3-11.

Hrabak Zerjavic V, Kralj V, Dika and Jelakovic B (2010) Epidemiology of hypertension, stroke and myocardial infarction in Croatia. MEDIX 16:102-107. 
Kanth R, Ittaman S and Rezkalla S (2013) Circadian patterns of ST elevation myocardial infarction in the new millennium. Clin Med Res 11:66-72.

Kelly MA, Rees SD, Hydrie MZI, Shera AS, Bellary S, O'Hare JP, Kumar S, Taheri S, Basit A, Barnett AH, et al. (2012) Circadian gene variants and susceptibility to type 2 diabetes: a pilot study. PloS One 7:e32670.

Kovanen L, Donner K, Kaunisto M and Partonen T (2015) CRY1, CRY2 and PRKCDBP genetic variants in metabolic syndrome. Hypertens Res 38:186-192.

Li Z, Zhang Z, He Z, Tang W, Li T, Zeng Z, He L and Shi Y (2009) A partition-ligation-combination-subdivision EM algorithm for haplotype inference with multiallelic markers: update of the SHEsis (http://analysis.bio-x.cn) Cell Res 19:519-23.

Lipkova J, Splichal Z, Bienertova-Vasku JA, Jurajda M, Parenica J, Vasku A and Goldbergova M P (2014) Period3 VNTR polymorphism influences the time-of-day pain onset of acute myocardial infarction with ST elevation. Chronobiol Int, 31(8), 878-90.

Martino TA and Sole MJ (2009) Molecular time: An often overlooked dimension to cardiovascular disease. Circ Res 105:1047-61.

Ohkura N, Oishi K, Fukushima N, Kasamatsu M, Atsumi GI, Ishida N, Horie S and Matsuda J (2006) Circadian clock molecules CLOCK and CRYs modulate fibrinolytic activity by regulating the PAI-1 gene expression. J Thromb Haemost 4:2478-2485.

Paschos GK, Ibrahim S, Song WL, Kunieda T, Grant G, Reyes TM, Bradfield CA, Vaughan CH, Eiden M, Masoodi M, et al. (2012) Obesity in mice with adipocyte-specific deletion of clock component Arntl. Nat Med 18:1768-77.

Scott EM (2015) Circadian clocks, obesity and cardiometabolic function. Diabetes Obes Metab 17:84-89.

Shi YY and He L (2005) SHEsis, a powerful software platform for analyses of linkage disequilibrium, haplotype construction, and genetic association at polymorphism loci. Cell Res 15:97-8.

Solé X, Guinó E, Valls J, Iniesta R and Moreno V (2006) SNPStats: a web tool for the analysis of association studies. Bioinformatics 22:1928-9.
Staels B. (2006) When the clock stops ticking, metabolic syndrome explodes. Nat Med 12:54-55.

Suarez-Barrientos A, Lopez-Romero P, Vivas D, Castro-Ferreira F, Nunez-Gil I, Franco E, Ruiz-Mateos B, Garcia-Rubira JC, Fernandez-Ortiz A, Macaya C, et al. (2011) Circadian variations of infarct size in acute myocardial infarction. Heart 97:970-976.

Takeda N and Maemura K (2010) Circadian clock and vascular disease. Hypertens Res 33:645-51.

Takeda N and Maemura K (2016) Circadian clock and the onset of cardiovascular events. Hypertens Res 39:383-390.

Thygesen K, Alpert JS, Jaffe AS, Simoons ML, Chaitman BR and White HD (2012) Third universal definition of myocardial infarction. Nat Rev Cardiol 9:620-33.

Tsai JY, Kienesberger PC, Pulinilkunnil T, Sailors MH, Durgan DJ, Villegas-Montoya C, Jahoor A, Gonzalez R, Garvey ME, Boland B, et al. (2010) Direct Regulation of Myocardial Triglyceride Metabolism by the Cardiomyocyte Circadian Clock. J Biol Chem 285:2918-2929.

Turek FW, Joshu C, Kohsaka A, Lin E, Ivanova G, McDearmon E, Laposky A, Losee-Olson S, Easton A, Jensen DR, et al. (2005) Obesity and metabolic syndrome in circadian clock mutant mice. Science 308:1043-1045.

Vukolic A, Antic V, Van Vliet BN, Yang Z, Albrecht U and Montani J (2010) Role of mutation of the circadian clock gene Per2 in cardiovascular circadian rhythms. Am J Physiol Regul Integr Comp Physiol 298:627-634.

WHO (2015) Global status report on noncommunicable diseases 2014. WHO, Geneva, 280 p.

Woon PY, Kaisaki PJ, Bragança J, Bihoreau MT, Levy JC, Farrall $M$ and Gauguier D (2007) Aryl hydrocarbon receptor nuclear translocator-like (BMAL1) is associated with susceptibility to hypertension and type 2 diabetes. Proc Natl Acad Sci U S A 104:14412-7.

Associate Editor: Angela M. Vianna-Morgante

License information: This is an open-access article distributed under the terms of the Creative Commons Attribution License (type CC-BY), which permits unrestricted use, distribution and reproduction in any medium, provided the original article is properly cited. 